\title{
Karotis stentlemede yaş ve peroperatif morbidite ilişkisi
}

\section{The association between age and peroperative morbidity in carotid stenting cases}

\author{
Gürdal ORHAN*1, Ergün DAĞLIOĞLU²
}

'Sağlık Bilimleri Üniversitesi, Ankara Numune Eğitim ve Araştırma Hastanesi, Nöroloji Kliniği, Ankara/TÜRKiYE

${ }^{2}$ Sağlık Bilimleri Üniversitesi, Ankara Numune Eğitim ve Araştırma Hastanesi, Beyin ve Sinir Cerrahisi Kliniği, Ankara/TÜRKiYE

\section{öz}

Amaç: Karotid arter stenozu ileri yaş olgularda görülen bir hastalıktır. Karotid stenozu tedavisinde uygulanan karotis stentlemede peroperatif morbidite ve mortalitenin yaşa bağlı arttığı belirtilmektedir.

Gereç ve Yöntem: Bu çalışmada Ankara Numune Eğitim ve Araştırma Hastanesinde 2017 Ocak ve 2018 Ağustos tarihleri arasında karotis stentleme yapılan 106 olgu analiz edilmiş olup yaş ve risk faktörleri ile peroperatif morbidite ve mortalite ilişkisi araştırılmıştır.

Bulgular: 106 olgunun analiz edildiği bu çalışmada 55 yaş altı görülen olgularda 2 olguda görülen hipotansiyon dışında herhangi bir morbidite gözlenmemiştir. 75 yaş ve üzeri olgularda ise hipotansiyon görülmemiş olup 55 yaş altı gruba göre daha fazla morbidite mevcuttur. 55-65 yaş arası yer alan grupta ise 1 olguda afazi, 1 olguda sol homonim hemianopsi, 1 mortalite olmuştur. 65-75 yaş arası grupta ise 2 olguda kısmi parezi, 1 olguda disfazi gözlenmiş ve 1 olguda postoperatif eksitus olmuştur. 75 yaş üzeri grupta ise 1 olguda silik hemiparezi, 1 olguda kranial sinir parezisi ve gözlerde deviasyon görülmüş olup postoperatif dönemde nöbet görülen 1 olgu ise eksitus olmuştur. Yaş artışı ile birlikte peroperatif morbidite ve mortalite oranlarında artış olduğu oransal olarak görülse de anlamlı bir istatistiksel sonuç elde edilememektedir. Hipotansiyonun ise yaşla birlikte azaldığı görülmektedir.

Sonuç: 55 yaş altı karotis stentlemede risk minimal olup hipotansiyon oransal olarak fazla görülmekte, 75 yaş üzeri grupta da hipotansiyon görülmeyip komplikasyonlar artış göstermektedir.

Anahtar kelimeler: yaş; karotid arter stentleme; peroperatif morbidite

Sorumlu yazar*: Gürdal Orhan, Sağlık Bilimleri Üniversitesi, Ankara Numune Eğitim ve Araştırma Hastanesi, Nöroloji Kliniği, Ankara/TÜRKiYE E-posta: gurdalorhan42@yahoo.com 


\section{ABSTRACT}

Aim: Carotid artery stenosis is a geriatric population disease. It was considered that advanced age is related to increased peroperative morbidity and mortality during carotid stenting.

Material and Methods:The study population includes 106 patients who were treated with carotid stenting at Ankara Numune Education and Research Hospital between January 2017 and August 2018 The aim of the study is to find the correlation between age and perioperative morbidity and mortality rates.

Results: The group of patients below 55 years of age didn't develop any morbidity except marked hypotension in 2 patients. Patients aged over 75 did not develop any hypotension and morbidity in this group is relatively high compared to patients below 55 years of age. Age group between 55 and 65 developed 1 aphasia, 1 homonymous hemianopia and 1 mortality. There were 1 dyspasia, 2 hemiparesis and 1 mortality in patients between 65 and 75 years of age. Morbidity over 75 years of age included 1 hemiparesis, 1 cranial nerve paresis and 1 mortality. No correlation was found between age groups except patients below 55 years of age. An increased morbidity and mortality rate was noted with advanced age though a statistical correlation can not be applied. Hypotension was noted to decrease with advanced age.

Conclusion: The risk of carotid stenting below 55 years of age is minimal except hypotension risk however perioperative morbidity and mortality is more pronounced with advanced age without any hypotension.

Keywords: age; carotid artery stenting; perioperative morbidity

\section{Giriş}

Karotid arter stenozu genel olarak geriatrik hasta grubunda görülen bir hastalıktır [1,2]. Karotid stenozu tedavisinde gerek endarterektomi ve stentleme etkin bir yöntem olup karşılaştırmalı pek çok çalışma mevcuttur [3,4]. Karotid stenozu tedavisinde stent ile tedavinin getirdiği morbidite ve mortalite riskinde yaşa bağlı bir artış olup olmadığı hakkında randomize ve çift kör çalışmalar oldukça kısıtlıdır. Ancak şu bir gerçektir ki ileri yaş olgularında aterosklerozdaki artış ve damarların tortiyositesi peroperatif morbiditeyi arttıran bir unsur olarak karşımıza çıkmaktadır $[5,6]$. Ayrıca yaş ilerledikçe artan komorbidite gibi pek çok faktör bu olgularda stentleme sırasında görülebilen komplikasyon riskini arttırmaktadır. Bu çalışmada Ankara Numune Hastanesinde 2017 Ocak ve 2018 Ağustos tarihleri arasında karotid arter stenozu nedeniyle stentleme yapılan 106 işlem ve 104 olgunun yaşa bağlı olarak morbidite ve mortalite riski analiz edilmektedir. Bu olguların peroperatif morbidite ve mortalitesi ile yaş ilişkisi arasındaki ilişkinin araştırıldığı bu çalışmada istatistiksel olarak bu 4 yaş grubu arasındaki fark analiz edilmektedir.

\section{Gereç ve Yöntemler}

Çalışma grubunda SBÜ Ankara Numune Hastanesi Nöroloji kliniği tarafından Nöroşirürji-Radyoloji kliniği ile birlikte klinik takip ve tedavisi gerçekleştirilen 106 karotis stent olgusunu içermektedir. Olguların başvuru tarihleri ele alınarak 2017 Ocak ve 2018 Ağustos tarihleri arasında tedavi edilen 106 stentleme analiz edilmektedir. Olguların en önemli risk faktörleri arasında hipertansiyon, diabetes mellitus, koroner arter hastalığı ve daha önce inme veya TIA (transient iskemik atak) benzeri bir atak geçirip geçirmediği yer almaktadır. Olgular yaşa göre 55 yaş altı, 55-65 yaş arası, 65-75 yaş arası grup ve 75 yaş üstü olmak üzere 4 gruba ayrılmaktadır.

Bu çalışmada yer alan tüm olgularda Protege RX karotis stent (Medtronic Inc., USA) karotis stent endovasküler olarak femoral arterden gönderilen bir uzun kılavuz kateter (sıklıkla Neuron MAX 088 guiding sheath, Penumbra Inc., USA) içerisinden gönderilmektedir. Femoral arterden sağlanan erişim ile lokal anestezi altında gerçekleştirilen tüm işlemlerde monitorizasyon ve gerektiğinde medikal müdahale uygulanacak şekilde hazırlık yapılmıştır. Hastaların büyük bir kısmında Spider FX embolik koruma sistemi (Spider FX embolic protection device, Medtronic Inc., USA) ve balon ile pre ve postdilatasyon uygulanmıştır.

\section{İstatistiksel Analiz}

İstatistik analizler OpenEpi istatistik programı kullanılmıştır (8). Kategorik değişkenlerin gösteriminde sayı ve yüzde dağılımlar kullanılmıştır. Yüzdeler arası farkın değerlendirilmesi için Binomial Oranlar için Tek Örneklem Testi kullanılmıştır. $p<0,05$ değeri istatistiksel anlamlılık sınırı olarak kabul edilmiştir. 


\section{Bulgular}

104 olgudaki 106 stentlemenin analiz edildiği bu çalışmada semptomatik ve semptomatik olmayan olgular bir arada analiz edilmektedir.

Karotis stentleme yapılan vakaların 11'i $(\% 9,8)$ koroner arter hastalığı tanısı alarak medikal tedavi almakta iken, 8'inin $(\% 7,1)$ koroner stent öyküsü, 20'sinin $(\% 17,9)$ ise koroner bypass cerrahisi geçmişi bulunmaktadır. Vakaların 59'unda $(\% 52,7)$ ise hipertansiyon, DM ve diğer risk faktörleri mevcuttur. Vakaların 14 'ünde $(\% 12,5)$ ise herhangi bir risk faktörü mevcut değildir. Toplam 104 olguda 112 risk faktörü (aynı olguda birden fazla risk faktörü görülebilmesi sebebiyle) analiz edilmiştir. Hipertansiyon, DM ve diğer risk faktörlerine sahip olma, risk faktörü olmamasına göre istatistiksel olarak anlamlı şekilde fazla iken $(p<0,001)$, diğer komorbidite sıklıkları ile risk faktörü olmama durumu arasında istatistiksel olarak anlamlı farklılık olmadığı bulunmuştur (Tablo 1).

\begin{tabular}{l|ccc|}
$\begin{array}{l}\text { Tablo 1: Karotis Stentleme Yapılan Vakaların Komorbidite } \\
\text { Görülme Sıklıkları }\end{array}$ & Sayı & Yüzde & $\begin{array}{c}\text { p } \\
\text { değeri }\end{array}$ \\
\hline \begin{tabular}{l|c|c|c} 
Koroner arter hastalığı olup medikal \\
tedavi alan
\end{tabular} & 11 & 9,8 & 0,391 \\
\hline $\begin{array}{l}\text { Koroner stent öyküsü olan } \\
\text { Koroner bypass cerrahisi olan }\end{array}$ & 8 & 7,1 & 0,086 \\
\hline $\begin{array}{l}\text { Hipertansiyon, DM ve diğer risk faktörleriolan } \\
\text { Risk faktörü olmayan }\end{array}$ & 59 & 17,9 & 0,086 \\
\hline Toplam karotis stentleme yapılan vaka & 112 & 12,5 & $<0,001$ \\
\hline
\end{tabular}

Karotis stentleme yapılan vakaların $35^{\prime}$ inde $(\% 33,0)$ inme hikâyesi bulunmamakta iken, 10'unda $(\% 9,4)$ ilk 24 saatte inme hikayesi, 27 'sinde $(\% 25,5) 6$ haftadan kısa süreli inme hikayesi ve 34 'ünde $(\% 32,1) 6$ haftadan uzun süreli inme hikayesi mevcuttur. Buna göre; ilk 24 saatte inme geçiren hastaların sıklığının inme-TIA öyküsü olmayanlara göre istatistiksel olarak anlamlı şekilde daha az prezente olduğu saptanmıştır $(p<0,001)$. Bununla birlikte 6 haftadan daha az süreli inme hikâyesi olma sıklığında ve 6 haftadan uzun süreli inme öyküsü olma sıklığında inme-TIA öyküsü olmama sıklığına göre anlamlı bir fark saptanmamıştır (sırasıyla $p=0,098$ ve $p=0,836$ ) (Tablo 2).

\begin{tabular}{|c|c|c|c|c|c|}
\hline & $\begin{array}{l}\text { Inme } \\
0-24 \\
\text { saat }\end{array}$ & $\begin{array}{l}\text { İnme } \\
<6 \\
\text { hafta }\end{array}$ & $\begin{array}{c}\text { İnme } \\
>6 \\
\text { hafta }\end{array}$ & $\begin{array}{c}\text { İnme-TIA } \\
\text { hikâyesi yok }\end{array}$ & $\begin{array}{c}\text { Toplam Karotis } \\
\text { Stentleme Yapılan } \\
\text { Vaka }\end{array}$ \\
\hline Sayı & 10 & 27 & 34 & 35 & 106 \\
\hline Yüzde & 9,4 & 25,5 & 32,1 & 33,0 & 100,0 \\
\hline p değeri & $=0,001$ & 0,098 & 0,836 & & \\
\hline
\end{tabular}

Karotisstentlemeyapılanvakalardakiperoperatifminörmorbidite geçirenlerin 1'i 55-65 yaş arasında, 1'i 65-75 yaş arasında ve 1'i 75 yaş üzerinde iken, majör morbidite geçirenlerin 1'i 55-65 yaş arasında, 2'si 65-75 yaş arasında ve 1'i 75 yaş üzerindedir. Mortalite gelişen vakaların 1'i 55-65 yaş arasında, 1'i 65-75 yaş arasında ve 1'i 75 yaş üzerindedir. Ayrıca derin hipotansiyon gelişen vakaların 2'si 55 yaş altında, 5'i 55-65 yaş arasında ve 2'si 65-75 arasındadır (Tablo 3). Burada görülme sayılarının azlığı nedeniyle istatistiksel olarak arada fark değerlendirilememektedir.

\begin{tabular}{|c|c|c|c|c|c|c|c|c|c|c|}
\hline & \multicolumn{10}{|c|}{ Yaş Dağılımı } \\
\hline & \multicolumn{2}{|c|}{$<55$ yaş } & \multicolumn{2}{|c|}{ 55-65 yaş arası } & \multicolumn{2}{|c|}{ 65-75 yaş arası } & \multicolumn{2}{|c|}{ >75 yaş } & \multicolumn{2}{|c|}{ Toplam } \\
\hline & Sayı & Yüzde & Sayı & Yüzde & Sayı & Yüzde & Sayı & Yüzde & Sayı & Yüzde \\
\hline Minör morbidite & 0 & 0,0 & 1 & 33,3 & 1 & 33,3 & 1 & 33,3 & 3 & 100,0 \\
\hline Majör morbidite & 0 & 0,0 & 1 & 25,0 & 2 & 50,0 & 1 & 25,0 & 4 & 100,0 \\
\hline Mortalite & 0 & 0,0 & 1 & 33,3 & 1 & 33,3 & 1 & 33,3 & 3 & 100,0 \\
\hline Derin hipotansiyon & 2 & 22,2 & 5 & 55,6 & 2 & 22,2 & 0 & 0,0 & 9 & 100,0 \\
\hline Toplam Vaka & 8 & 7,7 & 32 & 30,8 & 42 & 40,4 & 22 & 21,2 & 104 & 100,0 \\
\hline
\end{tabular}

55 yaş altı görülen olgularda 2 olguda görülen hipotansiyon dışında herhangi bir morbidite gözlenmemiştir. 55-65 yaş arası yer alan grupta (32 olgu) ise 1 olguda afazi, 1 olguda sol homonim hemianopsi, 1 olgu ise akut inme ile gelerek GCS 11 olan skoru postoperatif dönemde GCS 5 olmuştur. $\mathrm{Bu}$ olgu sonrasında eksitus olmuştur. Toplam 5 olguda ise hipotansiyon görülmüştür. 65-75 yaş arası grupta (42 olgu) ise 2 olguda kısmi parezi, 1 olguda disfazi gözlenmiş ve 1 olguda postoperatif eksitus olmuştur. 75 yaş üzeri grupta ise 1 olguda silik hemiparezi, 1 olguda kranial sinir parezisi ve gözlerde deviasyon görülmüş olup postoperatif dönemde nöbet görülen 1 olgu ise eksitus olmuştur

\section{Tartışma}

Bu çalışmada kliniğimizde karotid arter stenozu nedeniyle stentleme yapılan olgularda yaşa bağlı olarak morbidite ve mortalitenin ilişkisi araştırılmaktadır. Özellikle karotis stentleme yapılan olgularında risk faktörlerinden bağımsız olarak yaşın getirdiği morbidite ve mortalite riski önemlidir. 
Karotid arter hastalığı olan olgularda geçirilmiş inme ve TIA benzeri semptomların mevcudiyeti ve bunların peroperatif morbidite ve mortalite ile ilişkisi önemlidir. Stentleme yapılan olgularda özellikle koroner arter hastalığı mevcudiyetinin endarterektomi riskini arttırdığı bilinmektedir [8,9]. Özellikle 80 yaş ve üzeri grupta bu risk maksimum olarak bildirilmektedir [10]. Benzer şekilde hipertansiyon, diabetes mellitus ve benzeri komorbiditelerin karotis stentlemede peroperatif morbiditeyi arttırdığı düşünülmektedir.

Bu çalışmada yapılan yaşa bağlı analizde özellikle 55 yaş altında hemen hiçbir morbidite gözlenmeyip yaşın artması ile peroperatif morbidite ve mortalitenin arttığı gözlenmektedir. Yaşa bağlı morbidite ve mortalite riskinde artış olmakla birlikte yaş gruplarına göre yapılan analizde yaş artışı ile risk artışı arasında anlamlı bir ilişki saptanmamıştır. Yaşa bağlı risk faktörlerinin artışında özellikle arkus aorta, ana karotid arter ve diğer vasküler yapılarda kalsifikasyon ve aterosklerozda artışın peroperatif komplikasyonlardaki artış ile ilişkisi olduğu söylenebilir [5,6] Diğer yandan yaş arttıkça kardiyovasküler ve serebrovasküler olaylara karşı hassasiyetin arttığı söylenebilir. Benzer bir şekilde daha önce geçirilen inme veya TIA (geçici iskemik atak) benzeri bir tablo nedeniyle serebral rezervde yaşa bağlı düşme buna sebebiyet verebilir [11]. Karotis stentlemede yaş artışı ile riskin arttığına dair literatürde yapılan çalışmalar özellikle 75 yaş üzeri riskin arttığını işaret etmektedir [12-15]. Yaşı 55 ve altında olan karotis stentleme olgularında komplikasyonların oldukça az ve 75 yaş üstü olgularda ise peroperatif morbidite ve mortalitenin oransal olarak artması artan yaşın riski stentlemede riski arttırdığını göstermekle birlikte istatistiksel olarak anlamlı değildir. Tüm bunlara karşın artan yaş ile diabetes mellitus, hipertansiyon ve koroner hastalığı gibi pek çok komorbiditenin de arttığı düşünülerek bu komorbiditelerden bağımsız bir şekilde yaşa bağlı bir risk hesaplanması da ayrıca güçtür.

Karotis stentlemede postoperatif dönemde hipotansiyon önemli bir morbidite nedenidir [16-18]. Kontralateral karotis stenozu ve diabetes mellitusu olan olgularda hipotansiyonun daha fazla görüldüğü bildirilmiştir [17]. Preoperatif hipertansiyonu olup 2 ve daha fazla antihipertansif tedavi alan olgularda postoperatif hipotansiyonun daha çok görüldüğü saptanmıştır [16]. Ama tüm bunlara karşın literatürde postoperatif hipotansiyon ile diğer risk faktörleri arasında bir ilişkinin bulunamadığı çalışmalar da mevcuttur [19]. Bu çalışmada karotis stentleme işlemi sonrasında erken dönemde görülen hipotansiyonun 75 yaş üstü olgularda görülmemesi dikkat çekicidir. Özellikle 55 yaş altı grupta yer alan 8 olgunun 2'sinde (\%25) görülmesi, 55-65 yaş arası \%16 ve 65-75 yaş arası grupta ise \%4.8 oranında görülmesi yaşla birlikte hipotansiyon riskinin azaldığını göstermektedir. Bu bulgu daha önceki çalışmalarda yaşla birlikte artan ateroskleroz ve karotid arter duvar kalsifikasyonu gibi risk faktörlerinin de önemli olmadığını bildiren önceki çalışmaları kısmen destekleyen bir bulgudur $[17,18]$. Yaşta artış ile birlikte karotid arter duvarının elastisite ve hassasiyetinin azaldığı söylenebilir.

\section{Sonuç}

Karotis stentlemede yaşla birlikte peroperatif morbidite ve mortalite oranlarında artış görülmektedir. Özellikle 55 yaş ve altı olgularda risk minimal olup 75 yaş ve üzerinde ise peroperatif morbidite ve mortalite riski belirgin olarak artar.

\section{Çıkar çatışması / finansal destek beyanı}

Bu yazıdaki hiçbir yazarın herhangi bir çıkar çatışması yoktur. Yazının herhangi bir finansal desteği yoktur

\section{Kaynaklar}

1. Wendorff $C$, Wendorff $H$, Kuehnl A, Tsantilas P, Kallmayer M, Eckstein $\mathrm{HH}$, Pelisek J. Impact of sex and age on carotid plaque instability in asymptomatic patients-results from the Munich Vascular Biobank. Vasa 2016; 45: 411-16.

2. Ballotta E, Toniato A, Da Roit A, Lorenzetti R, Piatto G, Baracchini C. Carotid endarterectomy for asymptomatic carotid stenosis in the very elderly. J Vasc Surg 2015; 61: 382-88.

3. Mo D, Wang B, Ma N, Gao F, Miao Z. Comparative outcomes of carotid artery stenting for asymptomatic and symptomatic carotid artery stenosis: a single-center prospective study. J Neurointerv Surg 2016; 8: 126-29.

4. Rosenfield K, Matsumura JS, Chaturvedi S et al. Randomized Trial of Stent versus Surgery for Asymptomatic Carotid Stenosis. N Engl J Med 2016; 374: 1011-20.

5. Lam RC, Lin SC, DeRubertis B, Hynecek R, Kent KC, Faries PL. The impact of increasing age on anatomic factors affecting carotid angioplasty and stenting. J Vasc Surg 2007; 45: 875-80.

6. Lin SC, Trocciola SM, Rhee J et al. Analysis of anatomic factors and age in patients undergoing carotid angioplasty and stenting. Ann Vasc Surg 2005; 19: 798-804.

7. Sullivan KM, Dean A, Soe MM. OpenEpi: a web-based epidemiologic and statistical calculator for public health. Public health reports 2009; 124: 471-74. 
8. Nam HJ, Heo SH, Kim BJ, San Lee J, Youn HC, Lee JS, Kwon SU, Bushnell CD, Chang DI. Long-Term Outcome After Carotid Endarterectomy in Patients with Ischemic Heart Disease. World Neurosurg 2018; 110: 806-14.

9. Antoniou GA, Georgiadis GS, Georgakarakos El, Antoniou SA, Bessias N, Smyth JV, Murray D, Lazarides MK. Meta-analysis and meta-regression analysis of outcomes of carotid endarterectomy and stenting in the elderly. JAMA Surg 2013; 148: 1140-52.

10. Nanto M, Goto Y, Yamamoto H, Tanigawa S, Takado M, Ogawa T, Nakahara Y. Periprocedural Outcomes of Carotid Artery Stenting in Elderly Patients. J Stroke Cerebrovasc Dis 2018; 27: 103-7.

11. Roubin GS, lyer S, Halkin A, Vitek J, Brennan C. Realizing the potential of carotid artery stenting: Proposed paradigms for patient selection and procedural technique. Circulation 2006 113: 2021-30.

12. Antoniou GA, Georgiadis GS, Georgakarakos E, Antoniou SA, Bessias N, Smyth JV, Murray D, Lazarides MK. Meta-analysis and meta-regression analysis of outcomes of carotid endarterectomy and stenting in the elderly. JAMA Surg 2013; 148: 1140-52.

13. Qureshi Al, Chaudhry SA, Qureshi MH, Suri MF. Rates and predictors of 5 -year survival in a national cohort of asymptomatic elderly patients undergoing carotid revascularization. Neurosurgery 2015; 76: 34-41.
14. Ledwoch J, Staubach S, Segerer M, Strohm H, Mudra H. Carotid artery stenting in clinical practice depending on patient age. Catheter Cardiovasc Interv 2017; 90: 451-60.

15. Lin CM, Chang YJ, Liu CK, Yu CS, Lu HH. First-ever ischemic stroke in elderly patients: predictors of functional outcome following carotid artery stenting. Clin Interv Aging 2016; 11: 985-95.

16. Rubio G, Karwowski JK, DeAmorim H, Goldstein LJ, Bornak A. Predicting Factors Associated with Postoperative Hypotension following Carotid Artery Stenting. Ann Vasc Surg 2018 pii: S0890-5096(18)30571-5.

17. Gökçal E, Niftaliyev E, Deniz Ç, Ergelen $M$, Güzel V, Göktekin Ö, Asil T. Prolonged hypotension after carotid artery stenting: incidence, predictors and consequences. Acta Neurochir 2017; 159: 2081-87.

18. Cirbian J, Echaniz G, Gené A, Silva L, Fernández-Valenzuela V, de Nadal M. Incidence and timing of hypotension after transcervical carotid artery stenting: correlation with postoperative complications. Catheter Cardiovasc Interv 2014; 84: 1013-18.

19. Nanto M1, Goto $\mathrm{Y}$, Yamamoto H, Tanigawa S, Takeuchi H, Nakahara $\mathrm{Y}$, Tenjin $\mathrm{H}$, Takado M. Complications and Predictors of Hypotension Requiring Vasopressor after Carotid Artery Stenting. Neurol Med Chir 2017; 57: 115-21. 